\title{
Weight of the left and right ventricle of the heart during fetal life
}

\author{
ALISON HISLOP AND LYNNE REID \\ From the Department of Experimental Pathology, Institute of Diseases of the Chest, Brompton Hospital, \\ London
}

SYNOPSIS The hearts from 31 fetuses aged from 12 to 40 weeks' gestation were dissected after fixation. The right ventricle and the left ventricle plus septum were weighed separately and a ratio was established. The total and separate ventricular weights increase steadily with age and at a similar rate. Throughout fetal life the left ventricle plus septum is larger than the right ventricle, but the right ventricle forms a greater proportion of the total ventricular weight than it does in the child or the adult.

For the first time, a table of normal fetal heart weights and ratios obtained using the method of Fulton, Hutchinson, and Jones (1952) is presented.

Many methods have been used to estimate the relative weight of the ventricles both in the adult and during the fetal and childhood period of growth and hence to assess heart growth. Total heart weight was used by Smith (1928) but other authors weighed only the ventricular region, dividing this into septum, right and left ventricle, and either keeping the septum separate (Keen, 1955) or allotting it between the left and right ventricles in proportion to their respective weights (Muller, 1883; Lewis, 1914; Herrmann and Wilson, 1922).

Fulton et al (1952) showed that the septum behaved functionally as part of the left ventricle and they therefore separated only the free right ventricular wall, including the septum with the left ventricle. From this the normal weight range for the right ventricle and for the left ventricle together with septum was established for the adult heart as well as the ratio of the left ventricle and septum to right ventricle and the criteria of right and left ventricular hypertrophy. Davies and Reid (1970), using the same method, found that the adult ratio of left ventricle plus septum to right ventricle was reached at least by 10 months of age but, at birth, the right ventricle represented a greater proportion of the total. Recavarren and Arias-Stella (1964), using a different method, found the adult ventricular ratio to be present by 4 months. The purpose of this study was to estimate the heart weight during fetal life using the method of Fulton et al (1952).

Received for publication 7 March 1972.

\section{Material and Methods}

The hearts from 31 fetuses, aged between 12 and 40 weeks' gestation, were available for measurement. These hearts were all normal in structure and were obtained either from fetuses after abortion or from stillborn infants.

The hearts were fixed in buffered formol saline for at least one week, Millard (1965) having shown that by this time reduction in weight because of fixation shrinkage is complete. Each heart was dissected using the method of Fulton et al (1952). The atria and great vessels as well as the valve leaflets were separated from the ventricles. There is no fat to be removed from fetal hearts. The ventricles were then separated by cutting in the angle between the right ventricle and septum. The free right ventricle was removed leaving the left complete. Any papillary muscles on the right side of the septum were shaved off and included with the right ventricle. The ventricular muscle was weighed in two parts, the left ventricle plus septum $(L V+S)$ and the right ventricle (RV) and the ratio of $L V+S$ to $R V$ was calculated.

\section{Results}

The Table shows, for the 31 hearts, the age and total ventricular weight as well as the weight of the right ventricle, the left ventricle and septum, and the ratio of $\mathrm{LV}+\mathrm{S}$ to $\mathrm{RV}$. 


\begin{tabular}{|c|c|c|c|c|}
\hline Fetal Age (weeks) & Total Ventricular Weight $(\mathrm{g})$ & $R V^{1}(g)$ & $L V+S^{2}(g)$ & $\frac{L V+S}{R V}$ \\
\hline $\begin{array}{l}12 \\
14 \\
14 \\
14 \\
14 \\
14 \\
15 \\
16 \\
17 \\
17 \\
18 \\
18 \\
19 \\
19 \\
19 \\
19 \\
20 \\
23 \\
24 \\
26 \\
26 \\
26 \\
28 \\
28 \\
28 \\
31 \\
32 \\
34 \\
36 \\
39 \\
40\end{array}$ & 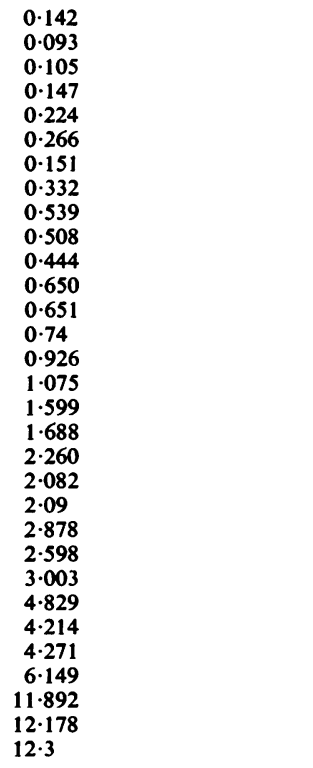 & $\begin{array}{l}0.068 \\
0.038 \\
0.042 \\
0.064 \\
0.091 \\
0.093 \\
0.056 \\
0 \cdot 16 \\
0 \cdot 212 \\
0 \cdot 228 \\
0 \cdot 196 \\
0.294 \\
0 \cdot 273 \\
0 \cdot 294 \\
0.384 \\
0.485 \\
0.649 \\
0.708 \\
0.805 \\
0.866 \\
0.674 \\
1.173 \\
0.955 \\
1.289 \\
1.658 \\
1.916 \\
1.667 \\
2.141 \\
5.774 \\
5.823 \\
5.6\end{array}$ & $\begin{array}{l}0.074 \\
0.055 \\
0.063 \\
0.083 \\
0 \cdot 133 \\
0 \cdot 173 \\
0.095 \\
0 \cdot 172 \\
0 \cdot 327 \\
0.38 \\
0.248 \\
0.356 \\
0.378 \\
0.446 \\
0.542 \\
0.59 \\
0.95 \\
0.98 \\
1.455 \\
1.216 \\
1.414 \\
1.705 \\
1.643 \\
1.714 \\
3.171 \\
2.298 \\
2.604 \\
4.008 \\
6.118 \\
6.355 \\
6.7\end{array}$ & $\begin{array}{l}1.08 \\
1.44 \\
1.5 \\
1.29 \\
1.46 \\
1.86 \\
1.69 \\
1.07 \\
1.54 \\
1.66 \\
1.25 \\
1.21 \\
1.38 \\
1.51 \\
1.4 \\
1.21 \\
1.46 \\
1.38 \\
1.807 \\
1.404 \\
2.09 \\
1.453 \\
1.72 \\
1.33 \\
1.91 \\
1.19 \\
1.56 \\
1.87 \\
1.06 \\
1.09 \\
1.2\end{array}$ \\
\hline
\end{tabular}

Table Ventricular weights in normal fetuses

${ }^{1} \mathbf{R V}=$ right ventricular weight

${ }^{2} \mathbf{L V}+\mathbf{S}=$ left ventricular + septal weight

The total ventricular weight increased steadily with age, the correlation coefficient being $0.9(\mathrm{P}=$ $<0.001)$. Although the absolute increase is greater in the second half of fetal life the rate of increase is greater during early gestation. Between 12 and 20 weeks the increase was about 11-fold, while over the next eight weeks it was three-fold, and during the next eight weeks about $2 \frac{1}{2}$-fold.

During fetal life the right ventricle and the left ventricle plus septum grow at a similar rate, the correlation coefficient between them being 0.9 . The left ventricle and septum are always larger than the right ventricle. The increase of the $\mathrm{LV}+\mathrm{S}$ as a percentage of its own weight at 12 weeks is greater than that of the RV to its own weight, but this may not be significant.

The ratio of $\mathrm{LV}+\mathrm{S}$ to $\mathrm{RV}$ varied considerably, the range being between 1.06 and 2.09 with a mean of 1.454 (SE, 0.048). There was no correlation between the ratio and either age or total ventricular weight. However, scrutiny of the figures for absolute weight indicates that over the earlier weeks of development the right ventricle may grow more slowly than the left but that over the latter part, that is after 28 weeks, it grows faster. Throughout fetal life the ratio was below the normal adult range of
$2 \cdot 3$ to $3 \cdot 3$, indicating a relative right ventricular preponderance.

There were in this series several ages at which more than one heart was available for dissection. A considerable variation at any age was found in total weight and also in the ratio: these varied independently.

\section{Discussion}

Harvey (1628) noted that the ventricles during fetal life were different from those of the adult in that the right and left ventricles were almost equal - like 'the double kernels of a nut'. The present results demonstrate a relatively large right ventricle during fetal life in comparison either with the adult or with the child over 10 months. Keen's (1955) series of infants at birth showed a similar weight for each ventricle to those of this series. He separated the septum from the left ventricle and found that without this the right and left ventricles were equal in size at birth. His results also demonstrated that the septum grew with the left ventricle rather than the right, supporting the theory of Fulton et al (1952).

In our series, throughout fetal life the weight of the left ventricle plus septum was greater than that 
of the right. Muller (1883) and Emery and Macdonald (1960) found that the right ventricle, which included the free wall and half the septum became heavier than the left after 28 weeks' gestation. In the present series, doubtless due to the different method, the right ventricle did not become heavier, but there was a relative increase in the rate of growth of the right ventricle during later fetal life.

Though using different techniques, all investigators have shown in the fetus an increased right ventricular mass relative to that of the left when compared with the adult values, the amount of difference varying with the method used. The right ventricular preponderance can be related to the high resistance of the fetal pulmonary blood vessels and to the increased percentage wall thickness in these vessels (Hislop, 1971). Davies and Reid (1970), using the present methods, have shown that the adult ratio is reached by 10 months though, because of their lack of younger material, it may be present earlier and, in fact, Recavarren and Arias-Stella (1964) suggested, using the method of Herrmann and Wilson (1922), that the adult proportion was reached by 4 months. There is a relative decrease in the right ventricle after birth. At the same time there is a gradual drop in wall thickness, complete in all vessels by 10 months (Hislop and Reid, 1972). This is the same age that the adult heart ratio is reached using the present method (Davies and Reid, 1970).

We are grateful to Dr H. Kay of the Royal Marsden
Hospital, Dr J. D. Lavertine of Hillingdon Hospital, and Dr J. Wigglesworth of Hammersmith Hospital for providing us with the fetal material used in this study.

\section{References}

Davies, G., and Reid, L. (1970). Growth of the alveoli and pulmonary arteries in childhood. Thorax, 25, 669-681.

Emery, J. L., and Macdonald, M. S. (1960). The weight of ventricles in the later weeks of intra-uterine life. Brit. Heart J., 22, क 563-570.

Fulton, R. M., Hutchinson, E. C., and Jones, A. M. (1952). Ventricular weight in cardiac hypertrophy. Brit. Heart J., 14, 413-421.

Harvey, W. (1628). Exercitatio Anatomica de Mortu Cordis. Fitzer Frankfort. (English trans., 1957. Movement of the Heart and Blood in Animals, translated from the original Latin by K. J. Franklin. Blackwell, Oxford.)

Herrmann, G. R., and Wilson, F. N. (1922). Ventricular hypertrophy, A comparison of electrosardiographic and postmortem of observations. Heart, 9, 91-147.

Hislop, A. (1971). The foetal and childhood development of the pulmonary circulation and its disturbance in certain types of childhood disease. PhD Thesis, London University.

Hislop, A., and Reid, L. (1972). Intrapulmonary arterial development 을 during childhood branching pattern and structure. (In preparation).

Keen, E. N. (1955). The postnatal development of the human cardiac ventricles. J. Anat. (Lond.), 89, 484-502.

Lewis, T. (1914). Observations upon ventricular hypertrophy, with especial reference to preponderance of one or other chamber.

Millard, F. J. C. (1965). The development and electrocardiographic diagnosis of right ventricular hypertrophy in chronic lung $N$ disease. MD Thesis, London University.

Müller, W. (1883). Die massenverhältnisse des Menschlichen Herzens. Voss, Hamburg and Leipzig. (Cited by Emery, J. L.., and Macdonald, M. S. 1960).

Recavarren, S., and Arias-Stella, J. (1964). Growth and development of the ventricular myocardium from birth to adult life. Brit Heart $J, 26,187-192$.

Smith, H. L. (1928-29). The relation of the weight of the heart to weight of the body and of the weight of the heart to age. Amer. Heart $J ., 4,79-93$. 